\title{
Declarações equativas tautológicas com nome próprio ${ }^{1}$ \\ Tautological equative statements with proper name
}

\author{
Márcia Teixeira Nogueira* \\ Leosmar Aparecido da Silva**
}

\section{RESUMO}

Este artigo tem o objetivo de analisar declarações equativas tautológicas com nomes próprios (Np) como Maria é Maria. Com suporte teórico em Wierzbicka (2003) e Meibauer (2008), bem como em trabalhos de Keizer (2008) e Hengeveld e Mackenzie (2008), o artigo apresenta, inicialmente, uma discussão teórica sobre os aspectos conceituais e funcionais da tautologia, bem como sobre a natureza referencial ou predicativa do nome próprio pós-cópula, para, em seguida, analisar dados coletados da internet, em que a estrutura $\mathrm{Np}$ é Np é usada. Os resultados revelam que as declarações equativas tautológicas com nome próprio, no contexto em que aparecem, constituem uma estratégia argumentativa por meio da qual se assevera a singularidade da representação mental de uma entidade discursiva, valorada positiva ou negativamente.

Palavras-chave: Tautologia. Declaração equativa. Nome próprio.

Recebido em 1 de junho de 2020

Aceito em 5 de novembro de 2020.

DOI: http://dx.doi.org/10.18364/rc.2021n61.450

*Universidade Federal do Ceará, marciatn@gmail.com, http://orcid.org/0000-0003-0307-7532

**Universidade Federal de Goiás, silva515@ufg.br, http://orcid.org/0000-0002-3954-3518

1 Este texto é um dos produtos gerados a partir do Estágio de pós-doutorado financiado pela CAPES por meio do Programa Nacional de Pós-Doutorado (PNPD).

Confluência. Rio de Janeiro: Liceu Literário Português, n. 61, p. 372-391, jul.-dez. 2021 


\section{ABSTRACT}

This paper aims to analyze tautological equative statements with proper noun (Np) like Maria is Maria. With theoretical support in Wierzbicka (2003) and Meibauer (2008), as well as in Keizer (2008) and Hengeveld and Mackenzie (2008), the paper initially presents a theoretical discussion on the conceptual and functional aspects of tautology, as well as on the referential or predicative nature of the post-copula proper noun, to then analyze data collected from the internet, in which the $\mathrm{Np}$ is $\mathrm{Np}$ structure is used. The results reveal that the tautological equative statements with proper noun, in the context in which they appear, constitute an argumentative strategy through which the singularity of the mental representation of a discursive entity, positively or negatively valued, is asserted.

Keywords: Tautology. Equative statement. Proper noun.

\section{Introdução}

Alguns estudos linguísticos (WIERZBICKA, 2003; MEIBAUER, 2008; ATAYDE, 2010) têm revisitado o tema das tautologias e identificado nelas valores semânticos e pragmáticos que justificam seu uso argumentativo em diferentes tipos de discursos. Uma tautologia é, tradicionalmente, tratada como um vício de linguagem, porque não acrescentaria nada além do que já foi dito. De acordo com Abbagnano (1982, p. 904), na terminologia filosófica tradicional, a tautologia, em particular nas definições, constitui um discurso vicioso enquanto inútil, porque repete, no predicado ou definiens, o conceito já contido no primeiro membro. Em termos de cálculo de predicado, uma declaração equativa como um pneu é um pneu² é tautológica, porque declara que um objeto é igual a si mesmo, sem a necessidade de verificar-se a referência desse objeto no mundo.

Em Silva e Nogueira (2018), a tautologia é tratada a partir das diferentes abordagens que ela tem recebido na Tradição Gramatical, na Lógica Proposicional, na Retórica e na Linguística. Com ênfase nos aspectos

2 Slogan de um centro automotivo em Fortaleza-CE: Gerardo Bastos. Onde um pneu é um pneu. 
semânticos e pragmáticos de seu uso em declarações, tratamos, neste artigo, de um tipo particular de tautologia, aquela que se manifesta por meio de uma predicação equativa com nomes próprios, do tipo Maria é Maria. O objetivo é analisar os aspectos semânticos e pragmáticos de ocorrências em um conjunto de dados coletados da internet. Partimos de uma discussão sobre os aspectos conceituais e funcionais da tautologia com base em Fraser (1988), Gibbs e McCarrel (1990), Meibauer (2008), Wierzbicka (2003), e incluímos, nessa discussão, uma revisão crítica feita por Keizer (2008), sobre declarações que envolvem nome próprio na posição pós-cópula. Tratamos, especificamente, das tautologias que envolvem a repetição de um nome próprio numa estrutura equativa do tipo $N p$ é $N p$. Em seguida, apresentamos os procedimentos metodológicos da pesquisa e a análise de ocorrências desse tipo de declaração tautológica com foco em seus aspectos semânticos e pragmáticos em cada contexto de uso.

\section{Tautologia: aspectos conceituais e funcionais}

Uma tautologia é conceituada, do ponto de vista da Lógica, como uma afirmação que, aplicados cálculos proposicionais, é verdadeira em relação a uma situação possível, mas pouco informativa, já que não adicionaria uma informação nova para o conhecimento do ouvinte (FRASER, 1988). Do ponto de vista linguístico, uma tautologia como Maria é Maria tem um componente lógico e, nesse sentido, será sempre verdadeira. Contudo, aspectos próprios da interação verbal contribuem para que essa declaração transmita uma mensagem, ainda que não imediatamente transparente (FRASER, 1988). Daí decorre o fato de alguns estudiosos como Atayde (2010) preferirem chamá-la de quase-tautologia.

Para Meibauer (2008, p. 442), as tautologias podem ser abordadas considerando-se quatro dimensões: 1) universalidade $\mathrm{x}$ especificidade das línguas; 2) convencionalidade x implicatura; 3) força ilocucionária; 4) estatuto predicativo do SN pós-cópula. 
Em relação à primeira dimensão, Meibauer (2008, p. 442) afirma que as tautologias equativas existem em muitas línguas. Contrapõe a opinião de Wierzbicka (1987; 1988), segundo a qual, cada construção tautológica tem um significado convencional específico de cada língua, à visão de Grice (1989), de que haveria uma invariante semântica nas tautologias que permitiria interpretálas por meio da aplicação de inferência informativa. O argumento de Wierzbicka $(1987,2003)$ é o de que o que é evidente, por si mesmo, em uma cultura pode ser questionado ou inaceitável em outra, e o que é visto como verdade fundamental em uma cultura pode ser visto como não verdade em outra.

Emrelação à segunda dimensão, a problemática refere-se à consideração das tautologias como construções idiomáticas ou expressões com significado lexical cristalizado. Meibauer (2008, p. 444) considera que os significados das tautologias são idênticos aos significados lexicais convencionalizados, mas que existem tautologias que podem não ser convencionais.

A terceira dimensão de tratamento da tautologia diz respeito a sua força ilocucionária. Meibauer (2008, p. 446) considera que há, pelo menos, três forças atuantes: a força da justificação ou da desculpa (guerra é guerra), a força da censura (uma regra é uma regra), a força do elogio (Brastemp é Brastemp).

Considerando tautologias equativas com SN no inglês, Fraser (1988, p. 217-218) propõe que essas declarações sinalizam:

i) que o falante deseja que o ouvinte reconheça que ele [falante] detém alguma visão em relação a todos os objetos referenciados pelo SN;

ii) que o falante acredita que o ouvinte pode reconhecer sua visão particular;

iii) que esta visão é relevante para a conversação.

Numa declaração como Guimarães Rosa é Guimarães Rosa... merece portanto o respeito de todos ${ }^{3}$, procura-se transmitir a crença de que

3 Comentário sobre um trecho de texto de Guimarães Rosa disponível em: <https:// br.answers.yahoo.com> Acesso: 28 maio 2020. 
os participantes compartilham uma visão a respeito de algum aspecto da entidade discursiva referenciada pelo $\mathrm{Np}$ da declaração e deseja trazer essa crença para a consciência do ouvinte.

Nesse sentido, a tautologia possui um componente metonímico, dado que um aspecto particular é encapsulado em uma construção que trata o ente como um todo. O modo diferente e peculiar de Guimarães Rosa exercer o papel social de romancista é apenas uma faceta de sua identidade como pessoa, mas a construção tautológica generaliza esse aspecto pontual como se todas as outras facetas também fossem peculiares. Para Gibbs e McCarrel (1990, p. 129), é necessário que, em construções tautológicas, o ouvinte reconheça a menção de que o todo se refere, na verdade, a alguma parte saliente desse todo.

Em relação à quarta dimensão, ou seja, ao estatuto predicativo do SN pós-cópula, há consenso, entre os estudiosos do tema, de que ele tem natureza predicativa, e não referencial. No entanto, quando o segundo SN é um nome próprio, a questão se complica, devendo ser considerada a possibilidade de esse SN ser analisado como referencial (numa declaração de identidade de referência) e não como predicativo. Por esse motivo, para tratar dessa importante questão, fazemos uma breve incursão nos trabalhos de Keizer (2008) e Hengeveld e Mackenzie (2008), especificamente sobre a discussão em torno da análise de declarações equativas com nome próprio após a cópula. Esse tipo de declaração coloca em pauta a diferença entre dois subatos básicos na constituição dos enunciados - referir e predicar.

$\mathrm{Na}$ ciência Linguística, as questões a respeito da referência têm sido tradicionalmente tratadas no âmbito da Semântica (FREGE, 1978 [1892]; LYONS, 1977). No entanto, na proposta da Gramática DiscursivoFuncional (GDF), referência e atribuição ${ }^{4}$ são descritos como subatos do Nível

4 Hengeveld e Mackenzie (2008, p. 108) tratam como Subato de Referência, a evocação de um referente (reference) e como Subato Atributivo (ascription), a evocação de uma propriedade, distinção que estamos tomando como correspondente à diferença entre os atos de referir e predicar, respectivamente. 
Interpessoal, ou seja, são relativos à Pragmática, ao uso que se faz da língua (natureza acional), e não ao Nível Representacional, atinente à Semântica.

Como uma declaração com a cópula, em especial aquela que contém um nome próprio na posição pós-cópula, constitui, para a análise linguística, uma fronteira difícil entre os atos de referir e predicar, Keizer (2008) faz uma interessante discussão sobre os problemas teórico-conceituais no tratamento desse tema. Trazemos aqui apenas alguns pontos dessa discussão, bem como a proposta da autora, para o entendimento de uma declaração em estrutura equativa com nome próprio, para, em seguida, estendermos esse entendimento à análise de declarações equativas tautológicas também com nome próprio ( $\mathrm{Np}$ é $\mathrm{Np}$ ).

Keizer(2008, p. 185) lembra que, já na Gramática Funcional, Dik (1989, 1997) passa a descrever as entidades referidas como entidades da mente, isto é, como parte do mundo mental, que não necessariamente correspondem ao mundo real, podendo ser uma representação de um mundo mítico, ficcional ou hipotético. Com relação às declarações de identidade discutidas em Frege (1978 [1892], como em The Morning Star is the Evening Star (A Estrela da Manhã é a Estrela da Noite) ${ }^{5}$, Keizer (2008, p. 192) chama a atenção para o fato de que não se trata de uma declaração de relação de identidade entre duas entidades do mundo real, nem entre nomes que designam essas entidades, mas entre entidades mentais separadas. $\mathrm{O}$ resultado de uma declaração de identidade comunicativamente informativa como essa é, portanto, um mundo mental em que duas descrições passam a aplicar-se a uma mesma entidade (ou seja, $x_{i}=x_{j}$, e não $\left.x_{i}=x_{i}\right){ }^{6}$

5 A identidade contida no clássico exemplo The Morning Star is the Evening Star é discutida em Frege (1978[1892]) em torno dos conceitos de referência e sentido. Frege conclui que a identidade aqui é uma relação entre objetos, mas mediada pelo sentido.

6 Na formalização da GDF, $x$ corresponde à categoria semântica Indivíduo, entidade de primeira ordem, que pode ser localizada no espaço e avaliada em termos da sua existência. (HENGEVELD; MACKENZIE, 2008, p. 131). Os índices diferentes formalizam a ideia de que os referentes, como representações mentais, são vistos como diferentes. 
Para Keizer (2008), em Eu sou Peter, o nome próprio é usado em um tipo especial de atribuição que, em vez de instruir o ouvinte a atribuir uma propriedade, ela o orienta a atribuir o rótulo Peter a uma entidade do discurso já introduzida ou, em outras palavras, a expandir o conjunto de extensão mental ${ }^{7}$ do nome Peter, abrigando, sob esse rótulo, mais uma entidade (a referida pelo pronome de primeira pessoa). Em português, é corrente uma declaração como Eu sou o Pedro como resposta a alguém que, ao telefone, afirma Gostaria de falar com o Pedro. Nesse contexto, estaria favorecida a interpretação de que se trata, nesse caso, de uma declaração de identidade entre duas entidades discursivas, sendo os dois SN tratados como referenciais.

E o que poderíamos dizer em relação a uma construção como $O$ Pedro é o Pedro, em que o mesmo nome próprio é utilizado antes e depois da cópula? Com base nas reflexões feitas por Keizer (2008), julgamos que, numa declaração desse tipo, a depender do contexto em que é utilizada, pode ser: a) uma declaração de identidade referencial entre duas entidades discursivas diferentes como representações mentais, não sendo, portanto, tautológica; b) uma construção tautológica ${ }^{8}$, em que o primeiro uso do nome próprio é referencial, mas o segundo tem natureza predicativa, é usado para reiterar, por meio do uso do mesmo nome próprio, uma única representação mental do falante, supostamente compartilhada pelo ouvinte, ressaltando-se a singularidade de uma entidade discursiva com características peculiares.

Supomos que o primeiro caso ocorre quando, por exemplo, o falante se dá conta de que alguém de nome Pedro, que ele conhece no seu ambiente de trabalho, é o mesmo rapaz, também chamado Pedro, de quem sua amiga sempre fala. Ambas são entidades identificáveis, com a mesma extensão mental relativa ao rótulo Pedro (homônimas), mas que eram representações

7 Definição de um conjunto de extensão mental: "The entire set of mental entities to which, in the view of speaker, the property (or properties) described by the lexeme(s) used in an expression applies (apply). (KEIZER, 2008, p. 202).

8 Ou construção quase tautológica, segundo Athayde (2010). 
mentais distintas antes da constatação enunciada em $O$ Pedro é o Pedro! Trata-se, portanto, de uma declaração de identidade comunicativamente informativa, que enuncia um mundo mental em que duas representações relativas a entidades diferentes passam a corresponder a uma mesma entidade. Em outras palavras, um mesmo nome próprio relativo a duas entidades distintas no mundo mental do falante passa a designar uma mesma entidade $\left(\mathrm{x}_{\mathrm{i}}=\mathrm{x}_{\mathrm{j}}\right)$. Com essa declaração de identidade, o falante enuncia que as duas representações passaram a ser uma só. Esse tipo de declaração não será objeto de análise neste artigo, já que o foco aqui são declarações tautológicas.

Já no segundo caso, temos a situação que identificamos, por exemplo, em $O$ Ronaldo é o Ronaldo! ${ }^{9}$ Essa declaração é utilizada para reforçar a identidade singular de uma única entidade discursiva, referida como identificável e definida no primeiro uso do nome próprio, e alvo da predicação contida no segundo uso do mesmo nome próprio, como estratégia de reiterar uma mesma representação mental que o falante tem dessa entidade. Nas tautologias em declarações equativas, o segundo uso do nome próprio, mais do que funcionar como a atribuição de um rótulo relativo a um conjunto de extensão mental (KEIZER, 2008), individualiza uma entidade e orienta o ouvinte a acessar, especificamente, uma representação mental já evocada no uso do nome próprio antes da cópula. Nesse segundo caso, podemos identificar, na declaração, uma tautologia pelo acesso a uma única entidade, enquanto representação mental, mesmo que por meio de dois subatos discursivos diferentes: o de referir e o predicar.

Consideramos que, na declaração O Ronaldo éo Ronaldo!, por meio do artigo definido e do nome próprio, o usuário da língua codifica um referente nominal identificável e acessível para o ouvinte. A definitude caracterizase, então, por ter natureza essencialmente pragmática e, por meio dos atos de referir e predicar, o falante pretende acessar, compartilhadamente, uma

9 Declaração do jogador José Fonte sobre o craque português Cristiano Ronaldo. Disponível em: <https://bit.ly/2TRwHSU>. Acesso: 29 maio 2020. 
representação pré-existente na mente do ouvinte (GIVÓN, 2001; KEIZER, 2008). O enunciado $O$ Ronaldo é o Ronaldo! implica dizer que há um ser no mundo conhecido do interlocutor que, por seus méritos como jogador de futebol, é suficientemente definível por si só. É um ser tão singular que, na avaliação do falante, a predicação mais adequada não é a atribuição de propriedades, mas a instrução tautológica de acesso a uma representação mental que já se tem do famoso jogador.

Feitas essas considerações sobre os aspectos conceituais e funcionais das tautologias em geral e, em particular, daquelas constituídas por nomes próprios, apresentamos, na seção seguinte, os procedimentos metodológicos utilizados na análise desse tipo particular de declaração tautológica em dados do português brasileiro.

\section{Procedimentos metodológicos}

Esta pesquisa tem abordagem qualitativa, pois concebe a existência de múltiplas construções da realidade por meio da língua, e apresenta-se como uma interpretação de dados concretos à luz das reflexões de natureza teórica empreendidas na seção anterior.

As ocorrências foram buscadas na plataforma Google (google.com). Utilizando-nos do recurso de aspas duplas, a declaração tautológica pretendida foi escrita no interior das aspas (“...”). A mesma declaração tautológica foi digitada duas vezes: uma com e outra sem o determinante, pois as tautologias com $\mathrm{Np}$, em sua forma, podem se realizar, como vimos, com ou sem a presença do artigo definido. Assim, em relação a representantes da música popular brasileira, por exemplo, digitou-se no buscador do Google "Roberto Carlos é Roberto Carlos" / "O Roberto Carlos é o Roberto Carlos" e também "Melchior é Melchior" / "O Melchior é o Melchior".

Ainda em relação à coleta de dados, a categorização dos tipos de entidades enumeradas por Neves (2000) serviu-nos de parâmetro para selecionarmos oito dimensões/entidades da vida social que os nomes próprios 
designam. Conforme o tipo de entidades, os nomes próprios buscados designavam: 1) representantes da literatura brasileira; 2) representantes do esporte: 3) representantes da música popular brasileira; 4) representantes políticos; 5) empresas; 6) espaços geográficos; 7) marcas/produtos; 8) festividades. As instâncias de 1 a 4 recobrem a busca por entidades subcategorizadas pelo traço semântico [+ humano]. As de 5 a 7 contemplam entidades com o traço [ + concreto]. E a instância de número 8 trata de entidades com traço [+abstrato]. O critério de escolha dos nomes próprios a serem buscados em sua realização em declarações equativas tautológicas (token) pautou-se pela representatividade e envergadura social da entidade no cenário nacional (e internacional). Pelo menos dois nomes próprios foram selecionados para integrar cada um dos oito tipos de entidades.

Não buscamos as ocorrências em corpora linguísticos já constituídos, porque as declarações equativas tautológicas com nome próprio não são tão frequentes, como atestado em consulta prévia a alguns bancos de dados do português brasileiro, tanto de fala como de escrita. Como o Google lida com os mais variados gêneros discursivos, foi possível selecionar 24 ocorrências de declarações tautológicas. A expectativa era a de selecionar, pelo menos, 32 ocorrências (4 para cada uma das oito dimensões/entidades). Contudo, declarações tautológicas sem o artigo definido foram menos frequentes. $\mathrm{Na}$ seção de análise e discussão dos dados, não analisaremos as 24 ocorrências, mas, por amostragem, somente as mais representativas.

\section{Análise e discussão dos dados}

Os resultados da análise apontam o uso de declarações tautológicas com nome próprio, presentes em diferentes tipos de gênero, tais como reportagens, blogs, comentários de blog e de reportagem, artigos de opinião e peças publicitárias.

Nomes próprios designam entidades únicas, segundo Neves (2000, p. 88), "de pessoas (antropônimos), lugares (topônimos), datas, festividades, 
marcas de produtos, livros, revistas peças, associações, agremiações, órgãos ou repartições, etc." Além disso, o nome próprio supõe um referente identificável e acessível para o interlocutor da interação. Como já era esperado, declarações tautológicas com nomes próprios designativos de entidades humanas foram mais frequentes em relação àquelas com nomes próprios designativos de entidades abstratas. A recorrência a marcas consagradas, empresas ou a pessoas públicas se deve, provavelmente, ao fato de os dados terem sido coletados no ciberespaço, que constitui, na atualidade, um importante espaço para divulgação de produtos e marcas, de exposição de pontos de vista sobre pessoas, lugares, fatos da vida social.

No contexto de uso de todas as ocorrências selecionadas, há valoração positiva ou negativa de uma empresa, marca ou pessoa, o que revela que a declaração tautológica funciona como um argumento conciso e eficaz para o convencimento e a persuasão do leitor. No uso de uma declaração equativa tautológica do tipo $\mathrm{Np}$ é $\mathrm{Np}$, parece haver a intenção de evocarse uma mesma representação mental de uma entidade discursiva. E isso se faz por meio do subato referencial realizado pelo $\mathrm{Np}$ antes da cópula e do subato atributivo que o mesmo $\mathrm{Np}$ realiza após a cópula, isto é, em posição predicativa, o que aciona conhecimentos partilhados e intersubjetivos entre os envolvidos no ato comunicativo. Essa estratégia tem, como efeito, a ênfase na singularidade dessa entidade, o que lhe confere uma importante função retórica no discurso.

Ocorrências como as descritas em (01), (02) e (03) a seguir, são construídas, com nomes próprios designativos, respectivamente, de personalidades do esporte, da música e da política.

(01) "Eu joguei tanto ou melhor do que Pelé em 1970. Tanto que a imprensa mundial me elegeu o jogador da Copa de 70. Então eu não sei o que dizer. É a imprensa daqui que fala que o Pelé é o Pelé”-disparou Jairzinho.

Declaração do Jogador Jairzinho do Futebol brasileiro e atuante na Copa de 1970. G1. 12 de maio de 2014. Disponível em: < https://glo.bo/3eyUor3> Acesso: 28 maio 2020. 
(02) Morador de Lins de Vasconcelos, no subúrbio do Rio, Jones Barbosa de Lima, de 55 anos, foi um dos primeiros a chegar [no show de Roberto Carlos], por volta das 7 h. Roberto Carlos é Roberto Carlos. Roberto Carlos é o cara. Escuto as músicas dele quantas vezes for e é sempre uma maravilha," diz o técnico de refrigeração, acrescentando que também foi um dos primeiros no show do Rei no Aterro do Flamengo. Fiquei 12 horas sem ir ao banheiro,"lembra.

Disponível em: < https://glo.bo/3dj7gSd > Acesso em: 06 set. 2019.

(03) Como Bolsonaro é Bolsonaro, tentou o caminho da truculência: Trump se comporta como garoto-propaganda da cloroquina e tenta ganhar o aval de especialistas para sem emprego em larga escala. Não encontrou especialista respeitável que tenha comprado a sua tese. Já o presidente brasileiro pensou até em baixar um decreto determinando o uso do remédio.

Reinaldo Azevedo. Trump, Bolsonaro e a cloroquina, que virou a cocaína da extremadireita. 08 abr. 2020. Disponível em: < https://bit.ly/36KjaBY> Acesso: 29 maio 2020.

Em (01), a tautologia com nome próprio empregada em discurso reportado (É a imprensa daqui que fala que o Pelé é o Pelé) é de valoração positiva à entidade discursiva Pelé, mas tal valoração é atribuída, pelo jogador Jairzinho, à imprensa, com a qual ele não concorda, já que afirma ter jogado tanto ou melhor do que Pelé em 1970. Jairzinho contesta a singularidade do jogador Pelé. Atribui essa valoração injusta à imprensa brasileira que, ao contrário da imprensa mundial que o elegeu o jogador da Copa de 70, insiste que Pelé é um jogador diferenciado dos demais, posição que ofuscou outros talentos, como o dele.

Em (02), há uma supervalorização da conhecida figura do cantor Roberto Carlos por meio do uso da tautologia Roberto Carlos é Roberto Carlos. Nela, a função predicativa do segundo uso do Np fica tão evidente que o próprio falante reelabora a tautologia na sequência do texto, dizendo que Roberto Carlos é o cara, no sentido de que a singularidade do popular cantor é indiscutível. Tendo a opção de predicar propriedades, mesmo as mais elogiosas, o fã de Roberto Carlos preferiu apresentá-lo como um cantor 
com excelência diferenciada, numa declaração tautológica que cumpre, com eficácia argumentativa, a evocação de uma representação mental que, segundo o entusiasmado fã do famoso cantor, é amplamente reconhecida e positivamente valorada.

Já em (03), a declaração tautológica Bolsonaro é Bolsonaro apresenta exterioridade em relação ao que se assevera na oração nuclear. Essa tautologia reforça uma representação mental que se tem de Bolsonaro, apresentada como causa de um comportamento previsível, que não poderia ser diferente sendo Bolsonaro quem é (Como Bolsonaro é Bolsonaro, tentou o caminho da truculência). Essa afirmação potencializa a força crítico-opositiva ao atual Presidente do Brasil, ao apresentar como amplamente compartilhada uma representação mental em que Bolsonaro é caracterizado como alguém de atitudes autoritárias. Essa tautologia, que também evoca a singularidade da entidade discursiva, tem valoração disfórica, embora a força ilocucionária pareça ser de justificação, no sentido de que não seria possível esperar de Bolsonaro uma reação equilibrada no contexto de combate à pandemia da Covid 19, sendo altamente previsível, portanto, que o Presidente pensaria na possibilidade de 'baixar um decreto determinando o uso do remédio [cloroquina]'.

No dado (04), a seguir, faz-se uso de uma tautologia com o nome de uma empresa brasileira de telecomunicação. Em um debate sobre cotas para negros no programa Na Moral, da Rede Globo, exibido no dia 10 de julho de 2014, a emissora fez um corte de um dos blocos do programa, em que o debate se transformou em bate-boca e confusão. Sobre o corte feito pela Rede Globo, o militante do Movimento Negro faz uso de uma tautologia com nome próprio:

(04) O militante do Movimento Negro lamenta o corte do debate no Na Moral, mas não ficou espantado: $\mathcal{O}$ debate foi acalorado desde o início. Uma pena não ter ido ao ar. Não estou frustrado, tampouco surpreso. $\boldsymbol{A}$ Globo é a Globo, jamais deixará de ser. Só lamento não ter podido levar para milhões de brasileiros nossa mensagem de combate ao racismo. $O$ país ainda se nega a debater e enfrentar este assunto."

Disponível em: < https://bit.ly/3dkRYMG> Acesso em: 06 set. 2019. Grifo nosso. 
A tautologia usada pelo integrante do Movimento Negro surge num contexto sociopolítico de oposição dos movimentos de ações afirmativas à Rede Globo, porque consideram-na manipuladora da opinião pública. Assim, quando o enunciador diz a Globo é a Globo, ele evoca impressões e conhecimentos compartilhados sobre a emissora, que dizem respeito, na visão do militante, à peculiaridade da emissora de agir de modo contrário aos interesses dos grupos minoritários em favor do interesse do capital, dos empresários, do colonizador branco.

Com a tautologia, o enunciador deixa subentender que "o modus operandi da emissora de 'esconder algumas verdades' é e será sempre o mesmo", "não tem como mudar", "é preciso se conformar com a situação". Algumas tautologias podem, de fato, evocar a ideia geral de aceitação, como na declaração Criança é criança! que sugere a tolerância que se deve ter com a atitude da entidade envolvida. Em relação ao dado analisado, contudo, a ideia de aceitação é apenas aparente, já que, ao dizer a Globo é a Globo, o ativista se mostra crítico em relação às atitudes da emissora. Reforça essa interpretação a afirmação do militante de que não estava surpreso com o corte do acalorado debate ocorrido no programa, o que significa dizer que não se poderia esperar algo diferente da parte da emissora.

A ocorrência a seguir, identificada no blog Tenso, traz um nome de um espaço geográfico na tautologia. No blog, é proposta uma enquete com a seguinte pergunta Como escapar de uma segunda-feira? Os usuários postam memes, dando resposta a essa pergunta e, em seguida, os leitores fazem comentários sobre tais memes. Sobre um que sugeria "ir para Bahia", porque "lá todo dia é Olodum, carnaval e festa", uma pessoa de naturalidade baiana assim faz seu comentário:

(05) AQUI NA BAHIA é um lugar que enquanto os turistas se divertem, até no Carnaval, o baiano trabalha, ganhando dinheiro dos turistas que acham que são espertos mais inteligentes e melhores.

Na Bahia é o lugar que as pessoas moram e vivem e onde vocês passam apenas as férias. 
Lá tem Sol, tem ar puro, enquanto onde você vive tem poluição e stress. A BAHIA tem praias onde nenhum lugar tem a sua beleza, onde você mora tem fumaça, tem preconceito e na BAHIA tem amor no coração, e onde as pessoas estão sempre de braços abertos para recepcionar pessoas como você (mesmo que você não mereça). Enfim, a BAHIA É $\boldsymbol{A}$ BAHIA! O RESTO É O RESTO.

Disponível em: < https://bit.ly/3eswkX0/>. Acesso em: 06 set. 2019.

Em (05), uma baiana se manifesta de maneira incisiva e crítica, dizendo que quem se diverte na Bahia, em plena segunda-feira, é o turista, enquanto o baiano trabalha. Acrescenta que o lugar onde mora o autor da resposta dada à pergunta feita pelo blog é poluído, estressante e sua população é preconceituosa, ao passo que a Bahia tem ar puro, sol, belas praias e um povo acolhedor, mesmo daqueles que não merecem essa acolhida. E conclui seu comentário com tautologias justapostas, escritas em letras maiúsculas. Faz, na primeira declaração, uma valoração positiva e, na segunda declaração, uma valoração negativa ( $a$ BAHIA É A BAHIA! O RESTO É O RESTO), ou seja, destaca a singularidade da Bahia em relação ao restante dos estados brasileiros. Como podemos constatar, três propriedades das tautologias são marcantes nesse dado: 1) a singularidade da entidade que é referida pelo primeiro uso do nome próprio e alvo de uma predicação no segundo uso desse mesmo nome próprio; 2) o convite indireto para a indiscutibilidade do tema, expresso pelo conjunto das tautologias coordenadas; 3) a contraposição entre o valor eufórico atribuído à Bahia e o valor disfórico atribuído ao que o falante chama de resto.

Devido à propriedade de agregar valor e por ter também função argumentativa, uma declaração tautológica com nome próprio do tipo $\mathrm{Np}$ é Np é usada pela publicidade não só para divulgar uma marca ou produto, mas também para torná-los lembrados como diferenciados em relação aos seus concorrentes. 
Em relação a marcas/produtos, identificamos um anúncio publicitário da rede de lojas de baterias Moura, que utiliza como slogan uma declaração tautológica com o nome da marca. Veja a seguir.

(06) Vá por quem entende. MOURA É MOURA.

Fonte: Disponível em: < https://bit.ly/2XJcosd >. Acesso em: 06 set. 2019.

A declaração tautológica Moura é Moura, antecedida pelo enunciado vá por quem entende, pode ser interpretada com o sentido de que as baterias Moura têm qualidade incomparável às outras marcas. Elas, por si só e por sua singularidade, garantem a excelência no desempenho elétrico do carro. Por meio do uso do mesmo nome próprio, primeiro em função referencial e, depois, em função predicativa, numa declaração tautológica em que o verbo ser está no tempo presente, omnitemporal, o veículo publicitário confere ao produto distinção entre os demais, qualidade, a propriedade de ser insubstituível. Importante observar que a declaração Moura é Moura apresenta-se sem o uso do determinante. Não foram encontrados dados para a tautologia $A$ Moura é a Moura, com o uso do determinante. Isso é significativo, porque há nuances de significado a serem considerados. Apesar de Moura ser um nome próprio, na propaganda, ele faz referência a um conjunto (plural) de baterias que têm esse rótulo, isto é, que pertencem a essa mesma marca. O objetivo da peça publicitária é contrapor a representação mental, supostamente positiva e amplamente reconhecida, das baterias nomeadas Moura com as de outras marcas de bateria. Isso enfraquece a premissa de que o nome próprio diz respeito a uma entidade particular, única, sendo também possível que haja coincidência entre o nome da marca e o nome da empresa, que, por sua vez, pode ter surgido como referência ao sobrenome de uma família.

O dado (07), a seguir, diz respeito a festividades. Nela, o diretor do torneio de tênis Rio Open fala da feliz coincidência de o evento ocorrer justamente nas datas do Carnaval do Rio de Janeiro em 2015, pois foi possível participar do torneio e do festejo do Carnaval: 
(07) O Carnaval é a maior festa do mundo. A gente não pode ignorare achar que o Rio Open é o Rio Open, e o Carnaval é o Carnaval. A gente acha que os dois vão bem juntos.

Lui Carvalho, diretor do Rio Open. 17 fev. 2015. Disponível em:<https://bit.ly/2ZULtMv>. Acesso: 29 maio 2020.

Carnaval é um nome próprio que designa um evento, não um indivíduo, um produto ou um lugar. Apesar disso, em (07), não há diferença semântica significativa em relação a tautologias com nomes próprios que designam entidades concretas e humanas. Há, no caso de nomes próprios relativos a festividades ou datas comemorativas, uma possibilidade maior de particularização (o Carnaval de 2020), embora não seja impossível realizar a fragmentação de uma entidade discursiva que, semanticamente, pertença à categoria de Indivíduo ( $O$ José adulto). Ainda que a representação mental de uma festividade como Carnaval seja mais difusa, menos claramente delineada do que, por exemplo, a de um cantor famoso, e, no amplo contexto social, esse tipo de entidade receba valorações bastante diferentes, é possível evocar, por meio de um nome próprio, uma representação com características amplamente conhecidas dessa festividade.

No dado (07), há duas tautologias coordenadas (o Rio Open é o Rio Open, e o Carnaval é o Carnaval), mas, ao contrário do que identificamos no uso de tautologias coordenadas do dado (05), não há uma valoração positiva para o primeiro e uma valoração negativa para o segundo evento. $O$ propósito aqui é ressaltar a singularidade e importância dos dois eventos, o famoso torneio de tênis (Rio Open) e o Carnaval, devendo ambos ser prestigiados.

\section{Conclusão}

Os dados contendo declarações equativas tautológicas com nome próprio analisadas neste texto comprovam que elas são utilizadas para reforçar uma representação mental singular de uma única entidade discursiva. No primeiro uso do nome próprio, a entidade é referida como identificável 
e definida e, no segundo uso do nome próprio, essa entidade é alvo de uma predicação, que cumpre a função de reiterar essa representação mental que o enunciador tem da entidade discursiva. Assim, uma mesma representação mental é acessada, respectivamente, pelos atos de referir e de predicar, numa construção como Roberto Carlos é Roberto Carlos.

Do ponto de vista linguístico, fica, então, relativizada a consideração dos estudos da Lógica de que há um vazio informativo nas tautologias. Se os dois nomes próprios têm natureza acional diferente em declarações equativas tautológicas, conforme defende Atayde (2010, p. 137), "elas deixam de ser consideradas 'redundantes' ou 'supérfluas', carreando, pelo contrário, um importante valor comunicativo". O uso linguístico, como vemos, "não se deixa reduzir às leis da lógica matemática" (ATAYDE, 2010). Além disso, eficácia comunicativa não significa pleno preenchimento informativo de formas verbais e nominais.

As tautologias analisadas neste artigo revelam, em uma única declaração, os usos referencial e atributivo dos nomes próprios. De fato, ainda que os nomes próprios não atribuam propriedades, eles podem ser utilizados predicativamente como instruções de acesso à representação mental de uma entidade cujos atributos se encontram socialmente compartilhados.

Os dados revelam, ainda, que as tautologias em declarações equativas com nome próprio ( $\mathrm{Np}$ é $\mathrm{Np}$ ), situadas contextualmente: 1) atuam na demarcação contundente do ponto de vista do enunciador que, com elas, pode valorar positiva ou negativamente a entidade discursiva e, portanto, tem forte atuação retórica; 2) podem ocorrer de modo independente, de modo coordenado a outra tautologia ou podem, ainda, ocorrer em cláusulas dependentes ou encaixadas. Em cada um desses modos de ocorrência, há diferentes efeitos. Numa tautologia justaposta ou coordenada a outra tautologia, por exemplo, é possível que se faça uma distinção enfática de categorias, com ou sem valoração. Na tautologia que se articula como cláusula dependente em relação à nuclear (isto é, com exterioridade em relação ao um conteúdo asseverado) pode-se reforçar, como pressuposta, uma representação 
mental numa crítica ou num elogio à entidade referida; 3) constituem, em alguns casos, convite à aceitação (real ou aparente) de um problema para o qual se julga não haver solução; 4) funcionam, em muitos casos, como convite à indiscutibilidade de uma representação do referente tratado; 5) são de fácil acesso à memória; 6) conferem caráter singular e atemporal de indivíduos, empresas, lugares, marcas/produtos, festividades, com o uso do verbo ser no presente do indicativo; 7) referem com maior ou menor grau de definitude a depender do tipo de entidade.

Cumpre dizer, ao final, que a análise desse tipo de declaração equativa tautológica revelou que o segundo uso do nome próprio serve ao propósito geral de reiterar a singularidade de uma única entidade discursiva, reconhecida por características peculiares da representação mental que dela tem o falante.

\section{Referências}

ABBAGNANO, N. Dicionário de filosofia. 2 .ed. São Paulo: Mestre Jou, 1982. ATAYDE, F. "Krieg ist Krieg ist Krieg” («Guerra é guerra é guerra») repetição e recriação no 'discurso fraseológico. Real - Revista de Estudos Alemães. Universidade de Coimbra, n. 1, p. 127 - 149, jul. 2010.

DIK, S. C. The theory of functional grammar. Dorderecht-Holland/ Providence: Foris Publications, 1989.

. The theory of functional grammar, part 2: complex and derived constructions. (Ed. by K. Hengeveld). Berlin/ New York: Mouton de Gruyter, 1997.

FRASER, B. Motor oil is motor oil; an account of English nominal tautologies. Journal of Pragmatics 12. North-Holland: Elsevier Science Publishers B. V., p. 215-220, 1988.

FREGE, G. Sobre o sentido e a referência. Lógica e filosofia da linguagem. São Paulo: Cultrix, 1978 [1892]. 
GIBBS, R. W. jr.; McCARREL, N. S. Why boys will be boys and girls will be girls: understanding coloquial tautologies. Journal of Psycholinguistic Research 19. p. 125-145, 1990.

GIVÓN, T. Syntax. Amsterdam/Philadelphia: John Benjamins Publishing Company, v. 1, 2001.

HENGEVELD, K; MACKENZIE, J. L. Functional siscourse grammar: a typologically-based theory of language structure. Oxford: Oxford University Press, 2008.

KEIZER, M. E. Reference and ascription in functional discourse drammar: an inventory of problems and some possible solutions. In: VELASCO, D. G.; RIJKHOFF, J. (Eds.). The Noun Phrase in Functional Discourse Grammar. Berlin and New York: Mouton de Gruyter, p.181-220, 2008.

LYONS, John. Semantics. Cambridge: Cambridge University Press, 1977.

MEIBAUER, J. Tautology as presumptive meaning. Pragmatics \& Cognition. 16:3. Amsterdam/Philadelphia: John Benjamins Publishing Company, p. 439470, 2008.

NEVES, M. H. M. Gramática de usos do português. São Paulo: Editora da UNESP, 2000.

SILVA, L. A. DA; NOGUEIRA, M. T. Construções tautológicas: tradição gramatical, lógica e argumentação. Revista de Letras, v. 2, n. 37, p. 194-209, 3 dez. 2018.

WIERZBICKA, A. Boys will be boys: radical pragmatics vs radical semantics. Language. 63, p. 95-114, 1987.

WIERZBICKA, A. Boys will be boys. A rejoinder to Bruce Fraser. Journal of Pragmatics 12. p. 221-224, 1988.

WIERZBICKA, A. Boys will be boys: even 'truisms' are culture-specific. In: . Cross-cultural pragmatics: the semantics of human interaction. Berlin, New York: Mouton de Gruyter, 2003. 